Check for updates

Cite this: Phys. Chem. Chem. Phys., $2020,22,22768$

Received 8th July 2020,

Accepted 20th August 2020

DOI: $10.1039 / \mathrm{d} 0 \mathrm{cp} 03639 \mathrm{k}$

rsc.li/pccp

\section{Towards standard electrolytes for sodium-ion batteries: physical properties, ion solvation and ion-pairing in alkyl carbonate solvents $\dagger$}

\author{
Damien Monti, (D) *abc Erlendur Jónsson, (D) ad Andrea Boschin, ${ }^{a}$ \\ M. Rosa Palacín, (iD bc Alexandre Ponrouch (iD bc and Patrik Johansson (iD ac
}

\begin{abstract}
The currently emerging sodium-ion battery technology is in need of an optimized standard organic solvent electrolyte based on solid and directly comparable data. With this aim we have made a systematic study of "simple" electrolyte systems consisting of two sodium salts (NaTFSI and NaPF 6 ) dissolved in three different alkyl carbonate solvents (EC, PC, DMC) within a wide range of salt concentrations and investigated: (i) their more macroscopic physico-chemical properties such as ionic conductivity, viscosity, thermal stability, and (ii) the molecular level properties such as ion-pairing and solvation. From this all electrolytes were found to have useful thermal operational windows and electrochemical stability windows, allowing for large scale energy storage technologies focused on load levelling or (to a less extent) electric vehicles, and ionic conductivities on par with analogous lithium-ion battery electrolytes, giving promise to also be power performant. Furthermore, at the molecular level the $\mathrm{NaPF}_{6}$-based electrolytes are more dissociated than the NaTFSI-based ones because of the higher ionic association strength of TFSI compared to $\mathrm{PF}_{6}{ }^{-}$while two different conformers of DMC participate in the $\mathrm{Na}^{+}$first solvation shells - a $\mathrm{Na}^{+}$affected conformational equilibrium and induced polarity of DMC. The non-negligible presence of DMC in the $\mathrm{Na}^{+}$first solvation shells increases as a function of salt concentration. Overall, these results should both have a general impact on the design of more performant $\mathrm{Na}$-conducting electrolytes and provide useful insight on the very details of the importance of DMC conformers in any cation solvation studies.
\end{abstract}

\section{Introduction}

The interest in rechargeable batteries, originating in prospects of better electrochemical storage and handling of green energy, is today larger than ever. To date, lithium-ion batteries (LIBs) are the leading electrochemical energy storage technology; they are omnipresent in the portable electronic field ${ }^{1-4}$ and electrical vehicles (EV), implemented also for large-scale grid applications, and even awarded the 2019 Nobel Prize in Chemistry. ${ }^{5}$ There is, however, an on-going debate on the availability of lithium from the Earth's crust and the supply

\footnotetext{
${ }^{a}$ Department of Physics, Chalmers University of Technology, SE-412 96 Göteborg, Sweden

${ }^{b}$ Institut de Ciència de Materials de Barcelona (ICMAB-CSIC) Campus UAB, E-08193 Bellaterra, Catalonia, Spain. E-mail: d.monti@csic.es

${ }^{c}$ Alistore-ERI European Research Institute, CNRS FR 3104, Hub de l'Energie, Rue Baudelocque, 80039 Amiens Cedex, France

${ }^{d}$ Department of Chemistry, University of Cambridge, Lensfield Road, Cambridge CB2 1EW, UK

$\dagger$ Electronic supplementary information (ESI) available. See DOI: 10.1039/ d0cp03639k
}

vulnerability owing to geopolitical development. ${ }^{6}$ Replacing lithium by sodium, both being alkali metals, is an attractive alternative particularly given its high abundance, hence its low cost. $^{6}$ Thus society at large as well as the overall battery market would greatly benefit from the sodium-ion battery (SIB) technology becoming competitive and thus a complement to LIBs. However, although the SIB development has been rapid since about 2010, the commercial impact remains small, especially as compared to LIBs. This is as much due to a lack of electrode materials matching the electrochemical performance of LIBs in terms of specific capacities and realized cell potential, but also stable and highly conductive electrolytes - reflected in the commercial skepticism towards SIBs until very recently. ${ }^{7-9}$

Investigations of SIB electrode materials are plentiful in the literature, ${ }^{10-15}$ while there are much fewer electrolyte studies made, especially such that take a broader perspective. ${ }^{16-18}$ SIB electrolytes more or less follow suit of LIB electrolytes. They are composed of cyclic carbonates e.g. ethylene and propylene carbonate (EC and $\mathrm{PC}$ ), and linear carbonates e.g. dimethyl, ethyl methyl, and diethyl carbonate (DMC, EMC and DEC) as solvents ${ }^{17,19}$ and are also combined with salts of similar nature 
and concentration - often $1 \mathrm{M} \mathrm{NaPF}_{6}$. In contrast to studies directed to LIBs, the bis(trifluoromethanesulfonyl)imide (TFSI) anion, here as NaTFSI salt, has received less attention ${ }^{20,21}$ due to its aluminium corrosion issues, as SIBs use aluminium current collectors at both the negative and positive electrodes. The TFSI anion is, however, both chemically and thermally more stable than the $\mathrm{PF}_{6}{ }^{-}$anion and does not lead to the formation of hazardous hydrogen fluoride (HF) to the same extent. ${ }^{22}$

While some attention has been given to the solid electrolyte interphase (SEI) ${ }^{23-25}$ formation and the electrochemical stability windows (ESWs) obtainable for SIBs, ${ }^{19,26,27}$ the basic electrolyte physico-chemical properties and their origins at the molecular level are still not well-studied. Yet, these properties profoundly affect both thermal and electrochemical stability windows, the insertion rates possible and the associated charge transfer resistance, ion transport, charge carrier speciation, etc. The nature of the charge carrying species in turn largely originates in the balance between ion-solvent and ion-ion interactions affecting most properties listed above. The charge carriers and the speciation in general, such as the extent of ion-pairing, can for example be evaluated using the Walden rule ${ }^{28}$ as used extensively for LIB electrolytes, ${ }^{29-32}$ or more directly by infrared, Raman, and nuclear magnetic resonance (NMR) spectroscopy, ${ }^{16,33-35}$ as well as by computational modelling approaches e.g. molecular dynamics (MD), MonteCarlo (MC), and density functional theory (DFT). ${ }^{16,21,36-38}$

Here a systematic experimental and computational study of physico-chemical properties and speciation is reported for "close to standard" SIB electrolytes over a broad range of salt concentrations. As their compositions are mimicking the standard LIB electrolytes - same anions and solvents, and the same practical macro-level properties are targeted, this paves the way for ample comparisons and to elucidate similarities and differences.

\section{Experimental}

\subsection{Materials}

Electrolytes were prepared by first mixing the solvents EC (anhydrous 99.0\%, Aldrich), DMC (battery grade, Merck), and PC (anhydrous $99.7 \%$, Aldrich) to result in EC:DMC $(1: 1)$ and EC:DMC:PC $(45: 45: 10)$ by weight (wt $\%)$. The salts NaTFSI (99\%, Solvionic) and $\mathrm{NaPF}_{6}(99 \%$, Strem Chemicals) were then used to create electrolytes of $\mathrm{NaX}\left(\mathrm{X}=\mathrm{PF}_{6}\right.$ or TFSI $)$ in EC: DMC $(1: 1)$ or EC:DMC:PC $(45: 45: 10)$ by direct addition of the proper amount of salt $\mathrm{NaX}$ to the solvent mixtures and stirring for $24 \mathrm{~h}$ at room temperature (RT). The resulting electrolytes are presented as $x \mathrm{M} \mathrm{NaX}$ in EC:DMC or $\mathrm{EC}_{0.45}: \mathrm{PC}_{0.45}: \mathrm{DMC}_{0.10}$ with $x$ ranging from $0.3-2.0$ and $0.3-1.4$ for the $\mathrm{NaPF}_{6}$ and NaTFSI based electrolytes, respectively. All samples were prepared inside an argon filled glove box with $<1$ ppm $\mathrm{H}_{2} \mathrm{O}$ and $0-5 \mathrm{ppm}_{2}$ and their water contents were $<30$ ppm $\mathrm{H}_{2} \mathrm{O}$ by Karl-Fischer titration (899 Coulometer/Metrohm).

\subsection{Methods}

2.2.1 Differential scanning calorimetry (DSC). DSC data were recorded on a Q1000 (TA instruments) calorimeter operating in the temperature range $-120{ }^{\circ} \mathrm{C}$ to $+40{ }^{\circ} \mathrm{C}$. A few $\mathrm{mg}$ of each sample were sealed in a hermetic aluminium pan inside the glove-box. All heating measurements were made using a scan rate of $10{ }^{\circ} \mathrm{C} \mathrm{min}^{-1}$. First the samples were cooled from $20{ }^{\circ} \mathrm{C}$ to $-120{ }^{\circ} \mathrm{C}$ without rate control, and equilibrated for $1 \mathrm{~min}$, then heated to $40{ }^{\circ} \mathrm{C}$. The glass transition temperatures $\left(T_{\mathrm{g}} \mathrm{s}\right)$ were determined as the inflection point of the heat capacity changes.

2.2.2 Dielectric spectroscopy. The ionic conductivities were measured using a Novocontrol broad-band dielectric spectrometer in the frequency range $10^{-1}-10^{7} \mathrm{~Hz}$ between $-10{ }^{\circ} \mathrm{C}$ and $60{ }^{\circ} \mathrm{C}$ with a step of $10{ }^{\circ} \mathrm{C}$. A constant volume $(0.14 \mathrm{~mL})$ cell was used, consisting of two brass (blocking) electrodes separated by a Teflon spacer (to contain the electrolytes and preventing any evaporation), which was sealed inside the argon filled glove-box. During the entire experiment, the cell was kept under a flow of dry $\mathrm{N}_{2}$ gas. The temperature was held constant for at least $20 \mathrm{~min}$ before each measurement to allow equilibration of the sample. Finally, the DC conductivities were extracted from the plateaus in the frequency dependent (AC) conductivity plots.

2.2.3 Viscometry. The viscosities were recorded between 10-60 ${ }^{\circ} \mathrm{C}$ as determined through the principle of a rolling ball (dynamic viscosity) on a Lovis $2000 \mathrm{M} / \mathrm{ME}$ (Anton Paar) instrument. The samples were filled in a $1.8 \mathrm{~mm}$ diameter capillary containing a steel ball.

2.2.4 Densitometry. The density data were recorded between $10-60{ }^{\circ} \mathrm{C}$ on a DMA $4500 \mathrm{M}$ (Anton Paar) instrument. $1 \mathrm{~mL}$ of each sample was introduced into a U-shaped borosilicate glass tube excited to vibrate at characteristic frequencies. The densities were derived from those frequencies.

2.2.5 Raman spectroscopy. For the Raman experiments, $1 \mathrm{~mL}$ of each sample was placed in a cylindrical cuvette of $2 \mathrm{~mL}$ which was sealed with paraffin tape inside the argon filled glove-box before being transferred to the Raman set-up. All measurements were made at RT using a Bruker MultiRAM FT-Raman spectrometer with a nitrogen-cooled germanium detector and at a resolution of $2 \mathrm{~cm}^{-1}$. In order to optimize the signal-to-noise ratio and avoid luminescence a Nd-YAG $(1064 \mathrm{~nm})$ laser was used as excitation source at an operating power of $500 \mathrm{~mW}$ and the spectra were averaged over 1000 scans. For a few selected electrolytes band-fitting and deconvolution were made in order to analyze in detail the $\mathrm{Na}^{+}$speciation. In the analysis stage, each band used was fitted using a Voigt function and four models were elaborated upon by considering the position, the width, and the mix of Gaussian and Lorentzian band-shape contributions (successively fixed).

2.2.6 Infrared spectroscopy. For infrared experiments, one electrolyte droplet was placed swiftly on the sample support from a sealed vial and measurements were limited to 12-15 seconds to limit air exposition. All measurements were made at RT using a Jasco 4700 FT-IR spectrometer with a resolution of $1 \mathrm{~cm}^{-1}$ for 15 scans in the range $500-4000 \mathrm{~cm}^{-1}$. For the analysis, we used a band-fitting procedure similar to that applied to the Raman data, as explained above.

2.2.7 DFT calculations. As both anions employed are weakly coordinating anions, the computational study focused on the 
cation-solvent interactions - building a wide range of $\left[\mathrm{Na}(\mathrm{EC})_{x^{-}}\right.$ $\left.(\mathrm{DMC})_{y}\right]^{+}[x=0-6, y=0-6]$ complexes. While EC is a "rigid" molecule, DMC has three different conformers and four unique associated coordinating possibilities, here denoted as A (cis-trans), B (cis-trans), C (cis-cis), and T (trans-trans) (Fig. 1). All DMC conformers were initially used for all differently sized complexes and the nomenclature we use includes these, for example a $\mathrm{Na}^{+}$solvated by $1 \mathrm{EC}$ molecule and $3 \mathrm{DMC}$ molecules, all in $\mathrm{T}$ conformation, is denoted $\left[\mathrm{Na}(\mathrm{EC})_{1}(\mathrm{DMC})_{3 \mathrm{TTT}}\right]^{+}$. For the larger complexes, however, the $\mathrm{C}$ conformer/site proved intractable, while the A conformer/site was only found stable in complexes larger than $[\mathrm{Na}(\mathrm{DMC})]^{+}$.

A common way to define the cation solvation energy is:

$$
\Delta E_{\{\text {solv }\}}=E_{\left\{\mathrm{Na}(\mathrm{EC})_{x}(\mathrm{DMC})_{y}\right\}^{+}}-\left(E_{\mathrm{Na}^{+}}+x \times E_{\mathrm{EC}}+y \times E_{\mathrm{DMC}}\right)
$$

However, here we instead employ the cation binding energy, defined as:

$$
\Delta E_{\text {bind }}=E_{\left\{\mathrm{Na}(\mathrm{EC})_{x}(\mathrm{DMC})_{y}\right\}^{+}}-\left(E_{\mathrm{Na}^{+}}+E_{\left\{(\mathrm{EC})_{x}(\mathrm{DMC})_{y}\right\}}\right)
$$

While this requires an extra single-point calculation for each of the optimised structures with the $\mathrm{Na}^{+}$ion removed, it serves the purpose to reduce the variation due to solvent-solvent interactions. A priori, $\Delta E_{\text {bind }}$ should thus give a more valuable comparative measure than $\Delta E_{\text {solv }}$ as the solvent-solvent interactions are cancelled out and thereby emphasizing the cationsolvent interaction.

All structures were optimized at both the B3LYP/6-311+ $\mathrm{G}^{*}$ and M06-2X levels of theory and verified to be minima by calculating the second derivatives with respect to nuclear displacements. The vibrational frequencies and IR/Raman intensities/activities were obtained by analytic derivatives. Furthermore, single-point calculations M06-2X/6-311+G*// B3LYP/6-311 $+\mathrm{G}^{*}$ were made for the $x+y=4$ systems. The ultrafine grid option was used in all cases and all calculations were made using Gaussian 09. ${ }^{39}$
A

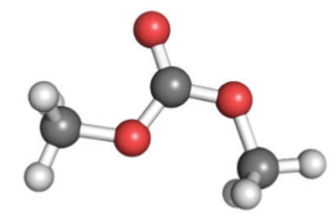

C

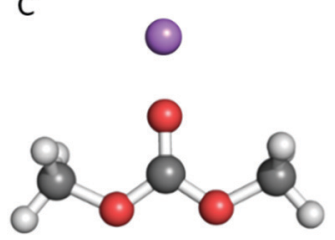

B

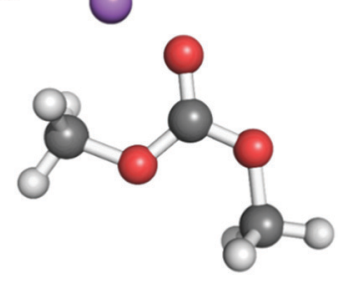

$\mathrm{T}$

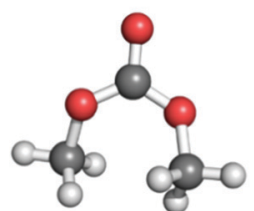

Fig. 1 The three different conformers of DMC and the four associated coordination sites as shown by $[\mathrm{Na}(\mathrm{DMC})]^{+}$: A (cis-trans), B (cis-trans), $\mathrm{C}$ (cis-cis) and T (trans-trans).

\section{Results and discussion}

As our goal was to observe how physico-chemical properties and molecular interactions are correlated we first evaluate the thermal and phase stability and how the salt concentration and interactions affect for example dynamic crosslinking. Second, we connect ionic conductivity and viscosity to the speciation via both experimental and computational studies of the $\mathrm{Na}^{+}$ first solvation shells. Finally, we create a synergetic picture of the electrolytes stretching from the molecular level to the macroscopic performance. In all of the above ample comparisons with standard LIB electrolytes are made.

\subsection{Thermal stability and glass transition temperature}

A wide window of thermal stability of the electrolyte is important as it broadens the application range of the SIBs. The nature of salts and solvents as well as the salt concentration all influence the molecular interactions and thus speciation ${ }^{40,41}$ and by this also phase transition temperatures.

The most important parameter is the crystallization temperature $\left(T_{\mathrm{c}}\right)$ as it sets the absolutely lowest operating and storage limit. The DSC heating traces of $x \mathrm{M} \mathrm{NaPF}_{6}$ and NaTFSI in EC:DMC $(x=0.3-1.4)$ have very similar behaviour (Fig. 2) with liquid ranges from $-30{ }^{\circ} \mathrm{C}$ to at least $40{ }^{\circ} \mathrm{C}$ for the highest salt concentration. For low salt concentrations three features are observed. While the feature at $10{ }^{\circ} \mathrm{C}$ is only slightly affected by the salt concentration, the feature at $-10{ }^{\circ} \mathrm{C}$ clearly moves to lower temperatures as function of salt concentration, to eventually merge with the third feature at $-25{ }^{\circ} \mathrm{C}$. All the electrolytes follow a similar trend; the formation of complexes increases as function of salt concentration and this also decreases $T_{\mathrm{c}}$.

In order to further interpret the DSC data, heating traces of pure DMC and EC were used. The EC trace has a melting peak at $40{ }^{\circ} \mathrm{C}$, while the DMC trace, and a fortiori the EC:DMC mixture, has features consistent with the electrolytes, albeit at slightly different temperatures (Fig. 3). Furthermore, as DMC-based species have been reported for LIB electrolytes to crystallize at $-23{ }^{\circ} \mathrm{C} \pm 10{ }^{\circ} \mathrm{C},{ }^{42,43}$ we conclude that all features between $-30^{\circ}$ and $20{ }^{\circ} \mathrm{C}$ likely are due to phase transitions coupled to DMC. In order to confirm this further, we used two different strategies: we either replaced EC:DMC by PC (Fig. S1, $\mathrm{ESI} \dagger$ ) or replaced a large proportion of the DMC by $\mathrm{PC}$ to formulate $\mathrm{EC}_{0.45}: \mathrm{PC}_{0.45}: \mathrm{DMC}_{0.10}$ (Fig. 3). As none of these systems have any features in this region, we conclude that DMC is the part of the electrolyte initiating the nucleation and subsequent crystallization.

Second in importance for thermal stability is the $T_{\mathrm{g}}$ as it reflects the overall dynamics of the electrolytes, including the dynamic cross-linking caused by ions and ionic complexes, ${ }^{44,45}$ which in turn affect macroscopic properties such as ionic conductivity or viscosity. There are discontinuities in the $T_{\mathrm{g}} \mathrm{S}$ for both Na-salt based electrolyte systems above $c a$. 1.0 M and these are also accompanied by exothermic peaks at $-65{ }^{\circ} \mathrm{C} \pm$ $10{ }^{\circ} \mathrm{C}$ (Fig. 2) from cold crystallization. ${ }^{46}$ Hence there is supercooling occurring which complicates the analysis. The corresponding PC-based electrolytes (Fig. S1, ESI $\dagger$ ), that also are 


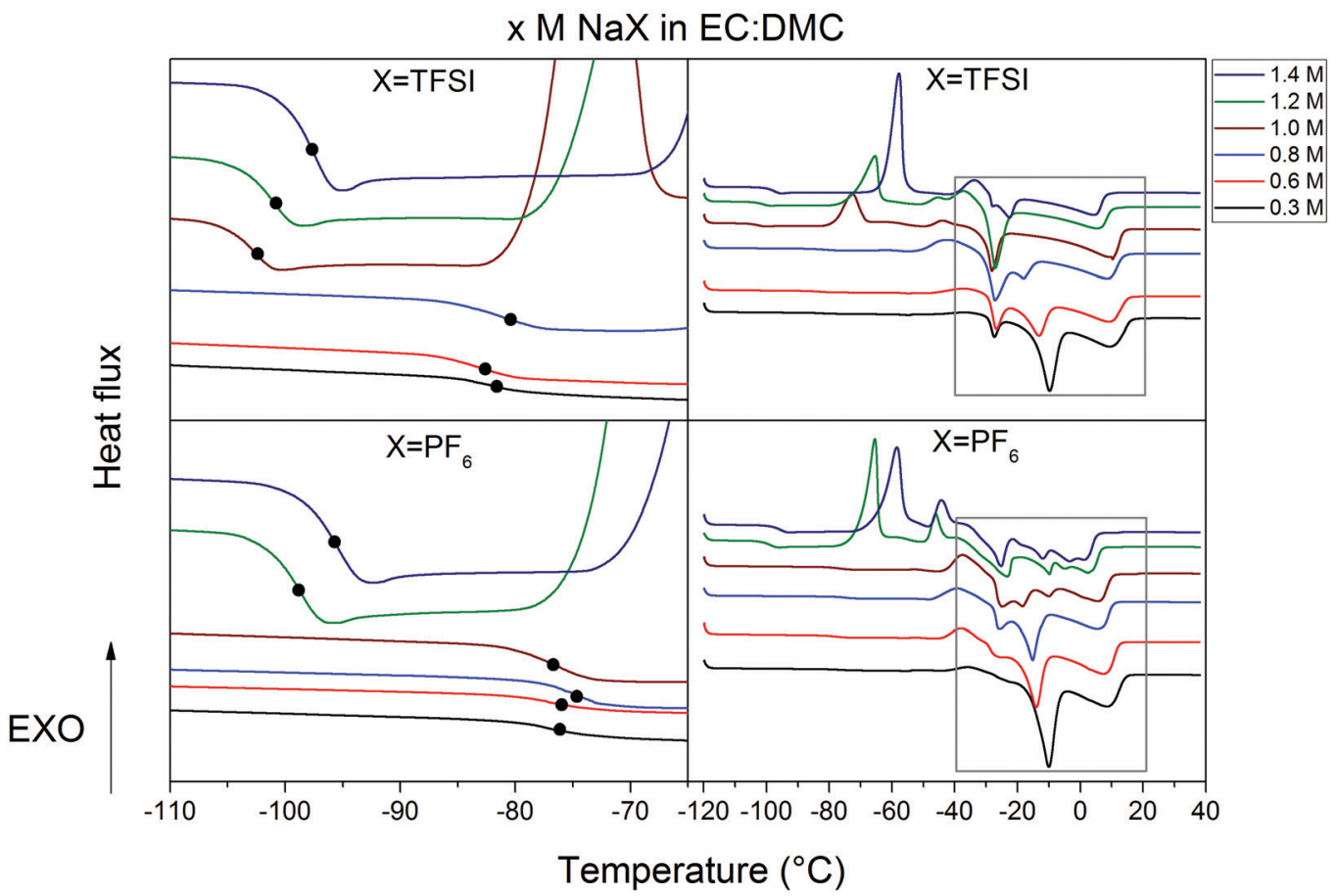

Fig. 2 DSC heating traces between $-120^{\circ} \mathrm{C}$ to $+40{ }^{\circ} \mathrm{C}$ (right column) for (top) $x \mathrm{M} \mathrm{NaTFSI}$ and (bottom) $x \mathrm{M} \mathrm{NaPF} 6$ in EC:DMC with $x=0.3,0.6,0.8,1.0$, 1.2, 1.4 (rectangles indicate regions of interest). The $T_{\mathrm{g}} \mathrm{s}$ (left column, black dots) are within $-110{ }^{\circ} \mathrm{C}$ to $-70{ }^{\circ} \mathrm{C}$.

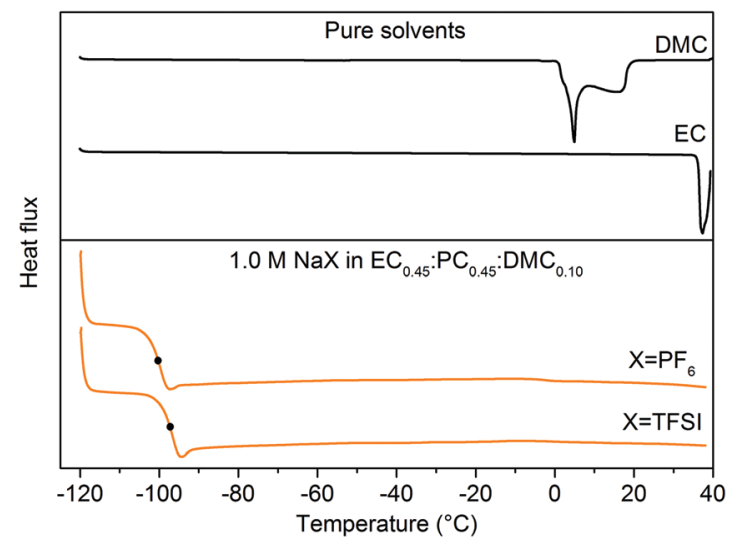

Fig. 3 DSC heating traces for (top) pure DMC and EC solvents, and (bottom) $1.0 \mathrm{M} \mathrm{NaX}$ in $\mathrm{EC}_{0.45}: \mathrm{PC}_{0.45}: \mathrm{DMC}_{0.10}\left(\mathrm{X}=\mathrm{TFSI}, \mathrm{PF}_{6}\right.$ ) electrolytes between $-120{ }^{\circ} \mathrm{C}$ to $+40^{\circ} \mathrm{C}$.

supercooled, do not show any cold crystallizations and for those the $T_{\mathrm{g}} \mathrm{s}$ increase linearly as functions of the salt concentration - as expected due to more dynamic cross-linking, ionpairing, and overall reduced dynamics. ${ }^{43}$

We can therefore assume that without any super-cooling effects, both our $x$ M NaX EC:DMC electrolyte systems would follow the same trend as function of salt concentration-as we already observed for IL-based Na-conducting electrolytes. ${ }^{47}$

In conclusion, the thermal behaviour of the electrolytes is very similar regardless of the salt used and the binary electrolytes undergo phase transitions only in the presence of a large proportion of DMC in the solvent formulation. The common useful operating temperature window for these SIB electrolytes is $c a .-20{ }^{\circ} \mathrm{C}$ to $40{ }^{\circ} \mathrm{C}$, quite similar to the corresponding LIB electrolytes. ${ }^{48,49}$

\subsection{Ionic conductivity, viscosity, and density}

Low viscosity foremost promotes fast ion transport, but is also important for proper wetting of porous electrodes and separators-although specific surface interaction affects wetting properties to a lower extend. The viscosities of our electrolytes increase as function of salt concentration and decrease with temperature (Fig. 4) following a Vogel-Tammann-Fulcher (VTF) behaviour, ${ }^{50-52}$ in accordance with the literature. ${ }^{53-55} \mathrm{The}^{\mathrm{NaPF}_{6}}{ }^{-}$ based electrolytes are in general slightly more viscous, but at lower temperatures $\left(10^{\circ} \mathrm{C}\right)$ the difference is only $0.8 \mathrm{mPa} \mathrm{s} v$ s. the NaTFSI-based electrolytes. Thus the changed speciation affects the viscosities similarly and this is also in accordance with the analogous LiB electrolytes; $\mathrm{LiPF}_{6}$ in EC:DMC is more viscous than LiTFSI in EC:DMC ${ }^{56}$ and with a very similar difference at $10{ }^{\circ} \mathrm{C}$ ( ca. $0.9 \mathrm{mPa}$ s). That our SIB electrolytes have slightly higher viscosities may indicate larger complexes being formed. ${ }^{37}$ The addition of $\mathrm{PC}$, as in $\mathrm{EC}_{0.45}: \mathrm{PC}_{0.45}: \mathrm{DMC}_{0.10}$, increases the viscosities and again the $\mathrm{NaPF}_{6}$-based electrolytes are both more viscous and have a larger change in viscosity.

Turning to the electrolyte densities, they matter very little for battery performance by their own, except when calculating the added weight of the electrolyte to the cell. It is re-assuring, however, that there are no discontinuities in the density data and these data are also needed for a proper Walden analysis of the electrolytes' ionicity.

As high enough ionic conductivities are ultimately needed for adequate battery performance, conductivity data should 

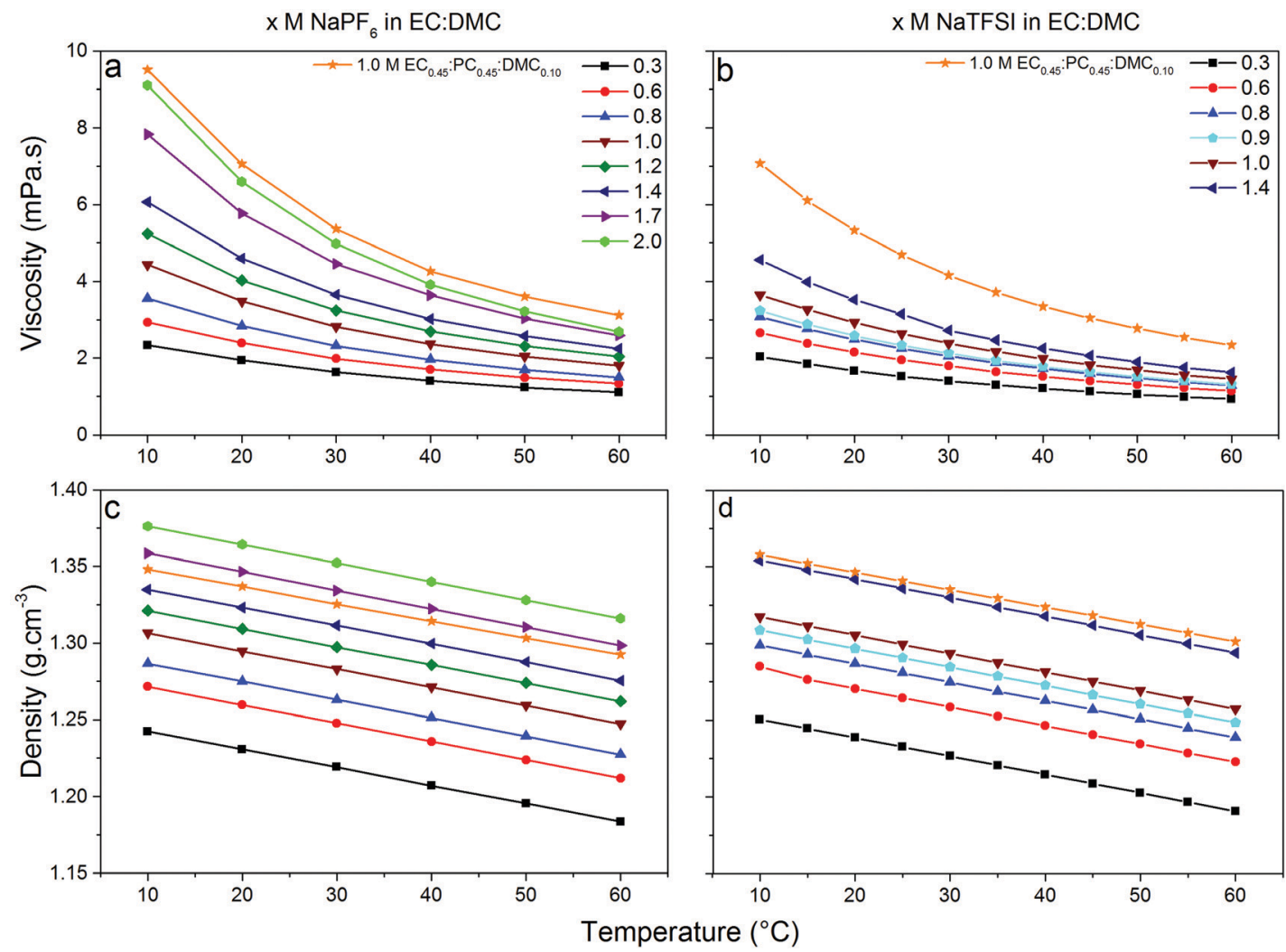

Fig. 4 Dynamic viscosities (top) and densities (bottom) between $+10{ }^{\circ} \mathrm{C}$ to $+60{ }^{\circ} \mathrm{C}$ of $x \mathrm{M} \mathrm{NaX}$ in EC:DMC and $1.0 \mathrm{M} \mathrm{NaX}$ in $\mathrm{EC}_{0.45}: \mathrm{PC}_{0.45}: \mathrm{DMC}_{0.10}$ (left: $\mathrm{X}=\mathrm{PF}_{6}$, right: $\mathrm{X}=\mathrm{TFSI}$ ) for concentrations $(x)$ ranging between $0.3-2.0 \mathrm{M}$ for $\mathrm{NaPF}_{6}$ and 0.3-1.4 $\mathrm{M}$ for $\mathrm{NaTFSI}$.

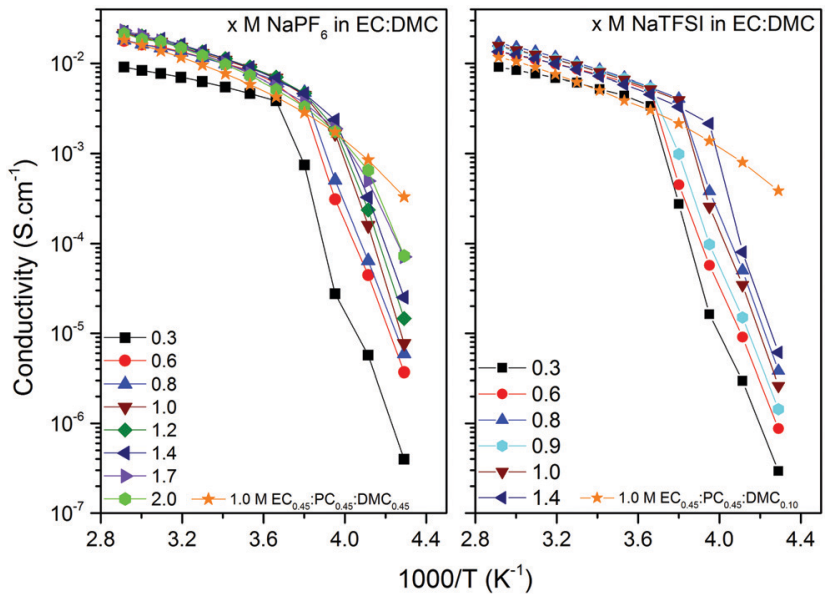

Fig. 5 Arrhenius plots of ionic conductivity between $+70{ }^{\circ} \mathrm{C}$ to $-40{ }^{\circ} \mathrm{C}$ for $x \mathrm{M} \mathrm{NaX}$ in $\mathrm{EC}: \mathrm{DMC}$ and $1.0 \mathrm{M} \mathrm{NaX}$ in $\mathrm{EC}_{0.45}: \mathrm{PC}_{0.45}: \mathrm{DMC}_{0.10}$ for concentrations $(x)$ ranging between $0.3-2.0 \mathrm{M}$ for $\mathrm{NaPF}_{6}$ and $0.3-1.4 \mathrm{M}$ for NaTFSI.

also be used to reveal operational temperature limits (Fig. 5). The discontinuities at low temperatures are consistent with the DSC analysis. Moving to RT, the $x \mathrm{M}$ NaTFSI and $\mathrm{NaPF}_{6}$ in EC:DMC electrolytes reach their maximum ionic conductivities of 8.5 and $11.2 \mathrm{mS} \mathrm{cm}{ }^{-1}$ for $x=1.0 \mathrm{M}$ and $x=1.2 \mathrm{M}$, respectively. This is similar to the analogous LIB electrolytes; at RT 1.0 M LiTFSI and $\mathrm{LiPF}_{6}$ in EC:DMC provide 9.4 and
$10.7 \mathrm{mS} \mathrm{cm}^{-1}$, respectively. ${ }^{53,57,58}$ In fact, these similarities extend over the whole temperature range. Furthermore, even the lowest salt concentration, $0.3 \mathrm{M}$, is acceptable for SIB application in terms of ionic conductivity $\left(>5 \mathrm{mS} \mathrm{cm}^{-1}\right.$ for both salts). Finally, as expected due to the increased viscosity by the addition of $\mathrm{PC}$, the $\mathrm{EC}_{0.45}: \mathrm{PC}_{0.45}: \mathrm{DMC}_{0.10}$ electrolytes have lower ionic conductivities; 5.0 and $7.6 \mathrm{mS} \mathrm{cm}^{-1}$ at RT, respectively. At the same time, however, the operating temperature window is extended as there are no discontinuities in the conductivity data - in accordance with the DSC data.

\subsection{Molecular level interactions and speciation}

Starting with the very basic DFT computed cation-DMC solvent interactions, the conformational equilibrium of DMC is clearly affected by the presence of $\mathrm{Na}^{+}$(Table 1 ) as the addition of either $\mathrm{Na}^{+}$or $\mathrm{Li}^{+}$changes the favoured conformer from the cis-cis (C) to the cis-trans conformer (A/B). For the molecule by itself, the enthalpic barrier of going from $\mathrm{C}$ to $\mathrm{A} / \mathrm{B}$ is calculated to be $c a .12 \mathrm{~kJ} \mathrm{~mol}^{-1}$, which is close to the experimental values (Table 1). The enthalpic difference is $17 \mathrm{~kJ} \mathrm{~mol}^{-1}$ in favour of A/B. The highly polar EC molecule should easily solvate the alkali cations, unlike the less polar DMC. However, the conformational equilibrium of DMC changes upon addition of $\mathrm{Na}^{+} / \mathrm{Li}^{+}$, and so will the induced polarity, shown as a change in dipole moment. Thus, any in-depth analysis of the cation solvation must take into account DMC and its conformers. Furthermore, as the conformers have slightly different 
Table 1 Dipole moments, $\mu$ (Debye) and enthalpy differences, $\Delta H\left(\mathrm{~kJ} \mathrm{~mol}^{-1}\right)$, between the DMC conformers with and without $\mathrm{Na}^{+} / \mathrm{Li}^{+}$

\begin{tabular}{llll}
\hline & $\mathrm{C}($ cis-cis $)$ & $\mathrm{A} / \mathrm{B}($ cis-trans $)$ & $\mathrm{T}($ trans-trans $)$ \\
\hline$\mu_{\exp }{ }^{61}$ & 0.35 & 3.1 & 5 \\
$\mu_{\text {B3LYP }}$ & 0.28 & 3.79 & 5.33 \\
$\mu_{\text {M06-2X }}$ & 0.2 & 3.82 & 5.29 \\
$\Delta H_{\text {exp }}$ & 0 & $10.0 \pm 0.8^{61}$ & $17.2 \pm 2.1^{61}$ \\
$\Delta H_{\text {B3LYP }}$ & 0 & $10.9 \pm 2.1^{62,63}$ & \\
$\mathrm{Li}^{+}$ & 17.2 & 11.9 & 67.5 \\
$\mathrm{Na}^{+}$ & 17 & 0 & 47.2 \\
$\Delta H_{\text {M06-2X }}$ & 0 & 0 & 48.4 \\
$\mathrm{Li}^{+}$ & 17.6 & 12.3 & 65.2 \\
$\mathrm{Na}^{+}$ & 16.8 & 0 & 46.2 \\
& & 0 & 46.6
\end{tabular}

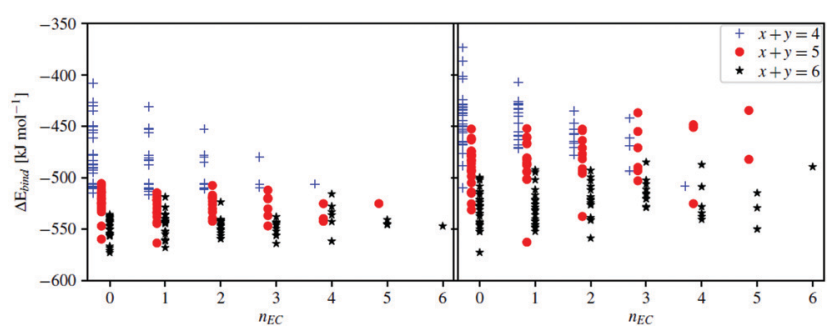

Fig. $6 \Delta E_{\text {bind }}$ for $\left[\mathrm{Na}(\mathrm{EC})_{x}(\mathrm{DMC})_{y}\right]^{+}(x+y=4 ; 5 ; 6)$; by B3LYP (left) and M06-2X (right).

vibrational spectra, they will also affect the Raman analysis and for proper comparisons we construct solvation complexes to reveal likely components of the $\mathrm{Na}^{+}$first solvation shell.

Moving to the complexes and starting with a $\mathrm{Na}^{+}$coordination number $(\mathrm{CN})=4$, i.e. the $x+y=4$ systems (Fig. 6), the B3LYP calculations (Table S1, ESI $\dagger$ ) predict a number of complexes to be more stable than the $\left[\mathrm{Na}(\mathrm{EC})_{4}\right]^{+} ;\left[\mathrm{Na}(\mathrm{EC})_{1}(\mathrm{DMC})_{3 т T \mathrm{TT}}\right]^{+}$, $\left[\mathrm{Na}(\mathrm{DMC})_{4 \mathrm{BBTT}}\right]^{+}$, and $\left[\mathrm{Na}(\mathrm{EC})_{1}(\mathrm{DMC})_{3 \mathrm{ATT}}\right]^{+}$, while the M06-2X calculations predict only one complex to be more stable: $\left[\mathrm{Na}(\mathrm{DMC})_{4 \mathrm{BTTT}}\right]^{+}$. Hence, the two different functionals show similar results, i.e. a mixture of EC and DMC in the $\mathrm{Na}^{+}$ first solvation shell, but the details differ. For B3LYP there are many complexes having energies close to that with the lowest $\Delta E_{\text {bind }}$ and taking into account the assumptions and limitations of the DFT calculations - the energetics are not sufficient to reveal the preferred solvation. The extra set of single point calculations, M06-2X calculations on the B3LYP geometries (Table S1, ESI $\dagger$ ), however, show that the main differences are due to geometry differences.

While a $\mathrm{CN}=4$ is rather well-founded for $\mathrm{Li}^{+}$in carbonatebased solvents, there is more of an uncertainty for $\mathrm{Na}^{+}$with respect to the preferred $\mathrm{CN}^{.59,60}$ Moving to higher CNs, but only with $\mathrm{EC}$ as solvent in the models, both $\left[\mathrm{Na}(\mathrm{EC})_{5}\right]^{+}$and $\left[\mathrm{Na}(\mathrm{EC})_{6}\right]^{+}$ are significantly more stable than $\left[\mathrm{Na}(\mathrm{EC})_{1}(\mathrm{DMC})_{3 \text { ттт }}\right]^{+}$.

The collection of data for $\left[\mathrm{Na}(\mathrm{EC})_{x}(\mathrm{DMC})_{y}\right]^{+}(x+y=4$, 5 and 6) strongly implies that a $\mathrm{CN}$ of 5 or 6 is preferred (Fig. 6). Furthermore, there is a large probability of DMC in the complexes, as many containing DMC have lower energies than $\left[\mathrm{Na}(\mathrm{EC})_{6}\right]^{+}$; the most stable is $\left[\mathrm{Na}(\mathrm{DMC})_{6 \mathrm{BTTTTT}}\right]^{+}$, with a few similar complexes with different DMC conformers within a narrow energy range, and other that differ in composition close in energy: $\left[\mathrm{Na}(\mathrm{EC})(\mathrm{DMC})_{5 \mathrm{BBTTT}}\right]^{+}$and $\left[\mathrm{Na}(\mathrm{EC})_{3}(\mathrm{DMC})_{3 \mathrm{TTT}}\right]^{+}$. This preference of $\mathrm{Na}^{+}$, in contrast to $\mathrm{Li}^{+}$, for a larger solvation shell has also been shown previously both for electrolytes ${ }^{64}$ and other solvents. ${ }^{65}$ While the energetics of complex formation is laden with several assumptions, these results form a base for the elucidation of different speciation and charge carriers present in the different electrolytes, and especially together with the experimental Raman data.

From a structural view-point, we observed large differences between the resulting complex geometries for the two functionals used. In general, the B3LYP functional resulted in more symmetric structures closer to what would be expected from "chemical intuition". To promote a further understanding of these differences and $v s$. the $\mathrm{Li}^{+}$analogues a few, selected amongst the more stable, complexes were analysed in more detail.

For example $\left[\mathrm{Na}(\mathrm{EC})_{4}\right]^{+}$has a close to tetrahedral symmetry $\left(T_{\mathrm{d}}\right)$ with a larger Na-O-C angle, in contrast to the $S_{4}$ symmetry computationally predicted and verified by Raman spectroscopy for $\left[\mathrm{Li}(\mathrm{EC})_{4}\right]^{+} .^{66}$ This is likely due to the smaller charge/radius ratio resulting in longer $\mathrm{Na}-\mathrm{O}$ distances and a reduced role of the carbonyl lone-pairs in controlling the coordination geometry. For $\left[\mathrm{Na}(\mathrm{EC})_{3}(\mathrm{DMC})_{1 \mathrm{~T}}\right]^{+}$the coordination of DMC clearly differs between the B3LYP and M06-2X results, the latter deviates from any resemblance of a $T_{\mathrm{d}}$ symmetry due to bidentate coordination of the $\mathrm{Na}^{+}$by the DMC, and thus the $\mathrm{CN}$ is rather 5 than 4 . Also for $\mathrm{CN}=5$ and $\mathrm{CN}=6$ there are many small but notable differences between the results from the two different functionals, which also agrees well with that the variance of the first solvation shell should be larger for the SIB electrolytes than for the analogous LIB electrolytes. ${ }^{38}$ More data on all the stable complexes obtained are found in the ESI. $\dagger$

Before moving from the computational predictions of the complexes present to the experimental verification - it is useful to use a few model systems and see what they imply for the spectroscopy data analysis. The ring breathing mode of EC, a common mode to analyse for cation coordination, ${ }^{66-68}$ a blueshift from 889 to $917 \mathrm{~cm}^{-1}$ is computed for $\mathrm{Na}^{+}$interaction. Likewise, for DMC (C) from 930 to $953 \mathrm{~cm}^{-1}$ and for DMC(A/B) from 867 to $880 \mathrm{~cm}^{-1}$. However, as the pure DMC conformational equilibrium is also affected by Na-salt addition, there is also a superposition of spectral changes arising due to different pure DMC conformers being present - not only the effect of $\mathrm{Na}^{+}$ complexation - and this will affect the data in a non-trivial manner - as also seen by ${ }^{13} \mathrm{C}$ NMR spectroscopy. ${ }^{33}$ Notably, the cation-induced shifts are considerably reduced for the larger complexes; for $\mathrm{Na}(\mathrm{EC})_{6}{ }^{+}$to $909 \mathrm{~cm}^{-1}$ (thus the induced shift is reduced by $\left.8 \mathrm{~cm}^{-1}\right)$ and for $\left[\mathrm{Na}(\mathrm{DMC})_{4 \mathrm{CCCC}}\right]^{+}$, $\left[\mathrm{Na}(\mathrm{DMC})_{6 \mathrm{GAAAAA}}\right]^{+}$, and $\left[\mathrm{Na}(\mathrm{DMC})_{6 \mathrm{BBBBBB}}\right]^{+} 944 \mathrm{~cm}^{-1}, 876 \mathrm{~cm}^{-1}$ and $877 \mathrm{~cm}^{-1}$, respectively.

Armed with the DFT computed relative energies and vibrational spectra data, we now turn to the Raman spectroscopy and the region $880-940 \mathrm{~cm}^{-1}$, which, as outlined above, contains bands originating from both EC and DMC (Fig. 7). The EC ring-breathing mode at $893 \mathrm{~cm}^{-167,68}$ shifts to $900 \mathrm{~cm}^{-1}$ upon $\mathrm{Na}^{+}$coordination, $4 \mathrm{~cm}^{-1}$ less than upon $\mathrm{Li}^{+}$coordination. ${ }^{66,69}$ 


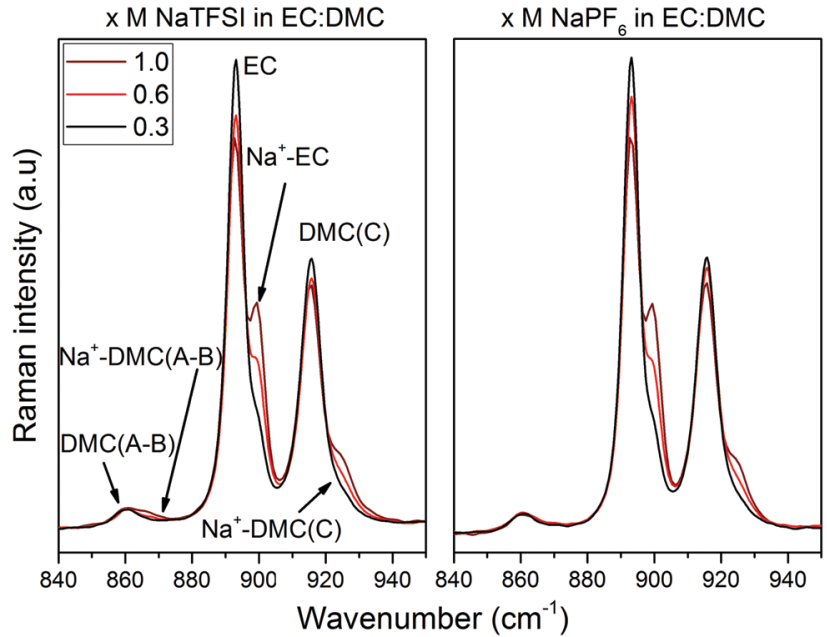

Fig. 7 Raman spectra of $x \mathrm{M}$ (left) NaTFSI and (right) $\mathrm{NaPF}_{6}$ in EC:DMC ( $x$ $=0.3,0.6,1.0)$ in the spectral range $840-950 \mathrm{~cm}^{-1} ; A, B, C$ being the DMC conformers and $\mathrm{Na}^{+}-\mathrm{EC}$ and $\mathrm{Na}^{+}-\mathrm{DMC}$ being the solvated molecules.

The $\mathrm{C}=\mathrm{O}$ stretching mode of $\mathrm{DMC}(\mathrm{C})$ shifts slightly more, from 915 to $925 \mathrm{~cm}^{-1}, 63,70$ which again is markedly less than for $\mathrm{Li}^{+}$ $\left(933 \mathrm{~cm}^{-1}\right){ }^{68,70,71}$ In addition, and as expected from the DFT calculations, $\mathrm{DMC}(\mathrm{A} / \mathrm{B})$ contributes to the $\mathrm{Na}^{+}$coordination, with bands at $860 \mathrm{~cm}^{-1}$ and $868 \mathrm{~cm}^{-1}$. That all shifts are smaller for $\mathrm{Na}^{+} v s . \mathrm{Li}^{+}$is a direct effect of a smaller charge/ radius ratio and concomitant weaker cation-solvent interactions. While not handled by the present DFT calculations, we also analyse the cation-anion interactions using the region $730-765 \mathrm{~cm}^{-1}$ containing the $\nu$ (SNS)/expansion and contraction band of the TFSI anion, "free" at $740 \mathrm{~cm}^{-1}$ and $\mathrm{Na}^{+}$coordinated at $744 \mathrm{~cm}^{-1}$ (Fig. 8a). ${ }^{47,72-75}$ For the $\mathrm{NaPF}_{6}$-based electrolytes we use infrared rather than Raman spectroscopy in the region of $800-900 \mathrm{~cm}^{-1}$ with the free $\mathrm{PF}_{6}{ }^{-}$asymmetrical stretching vibrational mode located at $844 \mathrm{~cm}^{-1},{ }^{76}$ while upon formation of contact ion-pairs (CIP) and aggregates (AGG) the $\mathrm{PF}_{6}{ }^{-}$symmetry is modified and altered into three bands: $833 \mathrm{~cm}^{-1}, 878 \mathrm{~cm}^{-1}, 33,77,78$ but also $853 \mathrm{~cm}^{-1}$. This has already been observed in $\mathrm{LiPF}_{6}$ in EC:DMC by Aroca et al. ${ }^{77}$ and Seo et $a .^{33}$ as these bands are the result of altered anion symmetry.

From all of the above combined, we extract positions of the (fitted) Raman bands and their associated Raman activities, and from this we calculate the relative contributions of EC, $\mathrm{DMC}(\mathrm{C}), \mathrm{DMC}(\mathrm{A} / \mathrm{B})$, and TFSI to the total solvation number (SN) of $\mathrm{Na}^{+}$(Table 2). For the $\mathrm{PF}_{6}$-based electrolytes the anion contribution could only be studied qualitatively as the vibrational modes associated to $\mathrm{Na}^{+}-\mathrm{PF}_{6}{ }^{-}$CIPs are not unambiguously defined. Each $\mathrm{SN}$ is determined as:

$$
\mathrm{SN}=\frac{A_{\mathrm{Na}^{+}-\mathrm{X}}}{A_{\mathrm{Na}^{+}-\mathrm{X}}+A_{\text {free- }}}
$$

where $\mathrm{X}$ is the studied ion (i.e. DMC, EC, TFSI, $\mathrm{PF}_{6}{ }^{-}$), while $A_{\mathrm{Na}^{+}}$. $\mathrm{x}, A_{\text {free-x }}$ are the R.A. normalized fitted areas of the coordinated and free species, respectively (Table 2). For all electrolytes the partial contributions of $\mathrm{SN}_{\mathrm{EC}}$ and $\mathrm{SN}_{\mathrm{DMC}(\mathrm{C})}$ decrease as function of NaTFSI salt concentration, while $\mathrm{SN}_{\mathrm{DMC}(\mathrm{ct})}$ significantly
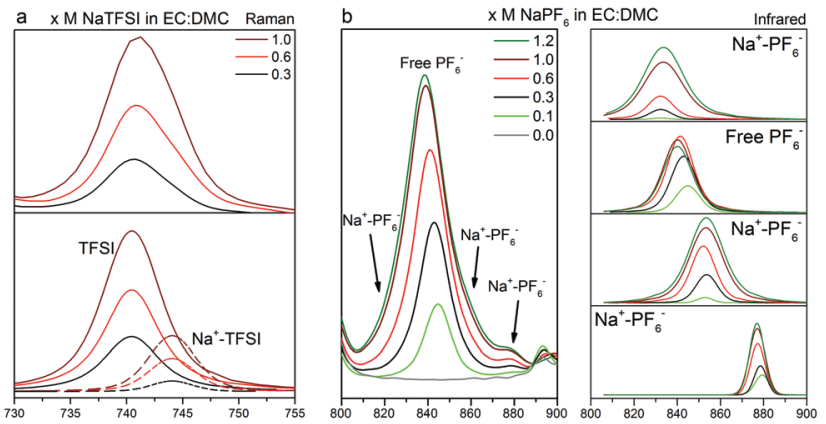

Wavenumber $\left(\mathrm{cm}^{-1}\right)$

Fig. 8 Raman spectra of (a) $x$ M NaTFSI in EC:DMC $(x=0.3,0.6,1.0)$ in the spectral range $730-755 \mathrm{~cm}^{-1}$, and IR spectra of (b, left) $\times \mathrm{M} \mathrm{NaPF}_{6}$ in EC:DMC $(x=0,0.1,0.3,0.6,1.0,1.2)$ in the spectral range $800-900 \mathrm{~cm}^{-1}$ with $(b$, right) the respective fitting peaks used for the deconvolution. The full range of IR spectra are shown in Fig. S2 (ESI $\dagger$ ).

contribute to the shell configuration with SN ranging between $0.16-0.21-10-15 \%$ of the total solvation number $\left(\mathrm{SN}_{\text {(total) }}\right)$.

Furthermore, $\mathrm{SN}_{\mathrm{EC}}$ decreases approximately twice as fast as $\mathrm{SN}_{\mathrm{DMC}(\text { total) }}$. Overall, EC predominantly solvates $\mathrm{Na}^{+}$at $0.3 \mathrm{M}$, while DMC contribute equally much at $1.0 \mathrm{M}$. $\mathrm{SN}_{\text {(total) }}$ decreases, as both $\mathrm{SN}_{\mathrm{EC}}$ and $\mathrm{SN}_{\mathrm{DMC}}$ decrease, which may be attributed to the increasing formation of CIPs and AGGs as they reduce the amount of solvation sites. ${ }^{79,80}$ In contrast, solvent separated ion-pairs (SSIPs) have a similar amount of solvent in their first solvation shells as complexed cations. ${ }^{81}$ Therefore, this may indicate that EC is preferentially removed from the $\mathrm{Na}^{+}$first solvation shell upon CIP/AGG formation - which agrees with the many stable complexes with several DMC included from the DFT calculations.

Moving to the ion-pair formation, CIPs/AGGs are present in both electrolytes and increase as a function of salt concentration (Fig. 8). However, the band at $740 \mathrm{~cm}^{-1}$ associated with TFSI increases constantly while the band annotated as "free" $\mathrm{PF}_{6}{ }^{-}$ seems to decrease after reaching a maximum between $0.6 \mathrm{M}$ and $1 \mathrm{M}$. For the latter system, this might indicate that the ratio between SSIPs and CIPs/AGGs changes in favour of CIP/AGG, while the total amount of ion-pairs constantly increases - a behaviour seen for $\mathrm{LiPF}_{6}$ in EC:DMC within the concentration range. ${ }^{33}$ This is further supported by changes in the spectra also for the "free" $\mathrm{PF}_{6}{ }^{-}$anion as the salt concentration increases.

For the same salt concentration the $\mathrm{NaPF}_{6}$-based electrolytes in average have $5 \%$ larger $\mathrm{SN}_{\text {(total) }}$ and this may, again, indicates that the NaTFSI-based electrolytes have proportionally more CIPs/AGGs, hence being less dissociated. This is, for example, in agreement with the detailed studies of $\mathrm{LiPF}_{6}$ and LiTFSI in acetonitrile, ${ }^{36}$ and thus agrees qualitatively across $\mathrm{Na}^{+}$to $\mathrm{Li}^{+}$. In the following part, we use the Walden rule to discuss and compare qualitatively the ionicity - degree of dissociation - in both electrolytes.

\subsection{Ionicity by Walden analysis}

While we above reported on molecular interactions and speciation in detail, the dissociation of the ions can also be studied using more macroscopic data by Walden analysis of the 
Table 2 Raman activities, average positions of Raman bands and SNs of EC, DMC (A, B, and C), and TFSI for $1.0 \mathrm{M}, 0.6 \mathrm{M}$, and $0.3 \mathrm{M}$ in either NaTFSI or $\mathrm{NaPF}_{6}$ in $\mathrm{EC}: \mathrm{DMC}$

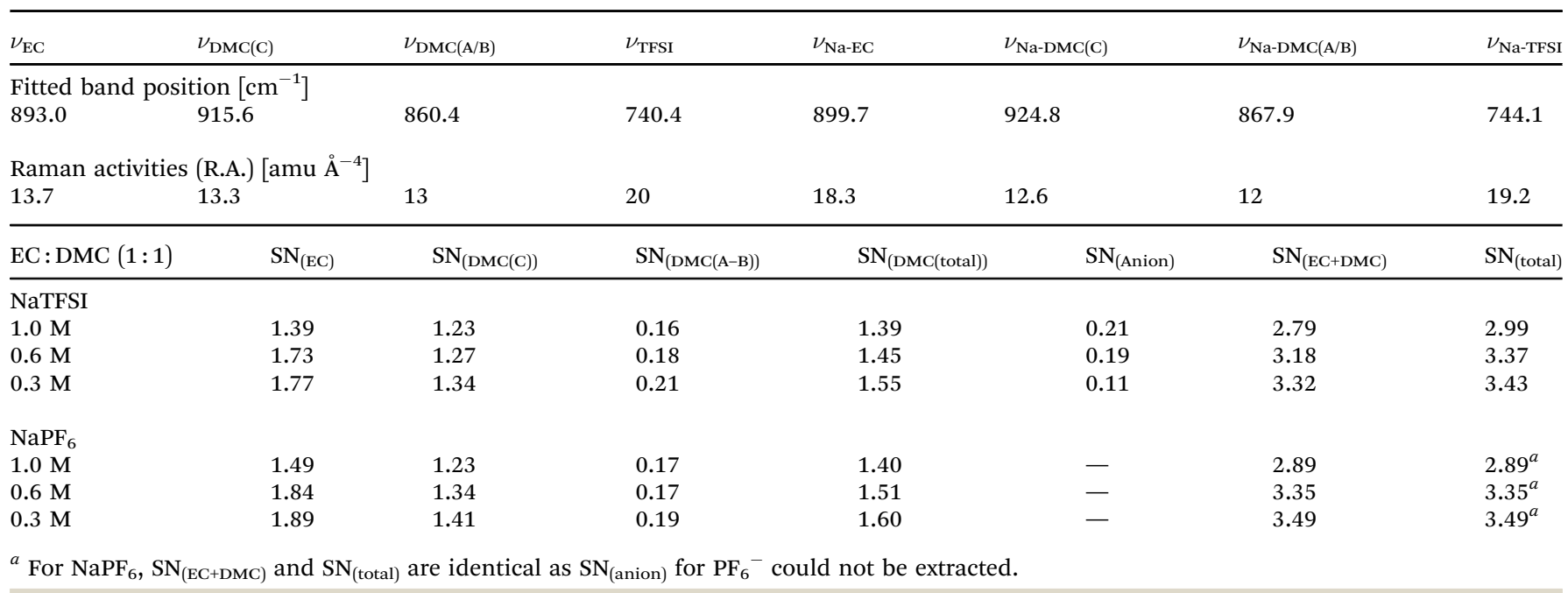

ionicity. The empirical Walden rule ${ }^{28}$ states that the product of the limiting molar ionic conductivity $\Lambda_{\mathrm{m}}^{\circ}$ and pure solvent's viscosity $\eta$ is a constant $(\approx 0.6)$ as expressed in (1). In (2) the logarithmic form of the equation used in Walden plots is provided. ${ }^{29,30}$

$$
\begin{gathered}
\Lambda_{\mathrm{m}}^{\circ} \cdot \eta=C=\text { constant } \\
\log \left(\Lambda_{\mathrm{m}}^{\circ}\right)=\log (C)+\log \left(\eta^{-1}\right)
\end{gathered}
$$

As more concentrated electrolytes have their ionic mobilities also impeded by other forces a factor " $\alpha$ " is introduced to a fractional Walden rule ${ }^{30}(3)$.

$$
\Lambda_{\mathrm{m}}^{\circ} \cdot \eta^{\alpha}=C^{\prime}=\mathrm{constant}
$$

As compared to a commonly used reference of $0.001 \mathrm{M} \mathrm{KCl}$ in water, with its ions known to be fully dissociated, ${ }^{53,82,83}$ albeit perhaps not be the best choice for non-aqueous electrolytes, ${ }^{30} \mathrm{a}$ downward deviation in a Walden plot implies a worse ion dissociation and lower ionicity. This is indeed the case for our $x$ M NaX in EC:DMC electrolytes, which also gradually move downwards as a function of salt concentration (Fig. 9). Again the $\mathrm{NaPF}_{6}$-based electrolytes are always closer to the reference and hence more dissociated, in agreement with the spectroscopic analysis.

From a Walden analysis perspective changing from EC:DMC to $\mathrm{EC}_{0.45}: \mathrm{PC}_{0.45}: \mathrm{DMC}_{0.10}$ based electrolytes, primarily changes the dielectric constant $(\varepsilon)$ and can thereby affect the ionicity. Indeed, while maintaining the order of the Na-salts the degree of dissociation seems to increase. In contrast, increasing the temperature is supposed to decrease $\varepsilon,{ }^{84,85}$ and while the temperature is not explicitly found in a Walden plot both the molar conductivities and the viscosities are temperature dependent, why a temperature increase can basically be followed diagonally from left to right. With $\alpha$ extracted for each of the electrolytes, $\alpha$ is $c a$. 0.7-0.9, which indicates that increasing the temperature also decreases the degree of dissociation.

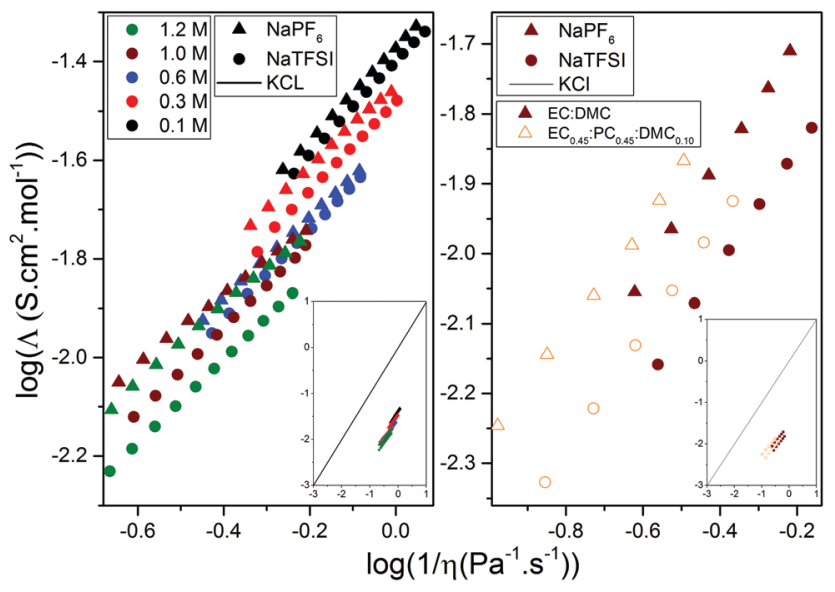

Fig. 9 Walden plots of (left) $x$ M NaTFSI or $\mathrm{NaPF}_{6}(x=0.1-1.2)$ in EC:DMC and (right) $1.0 \mathrm{M} \mathrm{NaTFSI}$ or $\mathrm{NaPF}_{6}$ in (full symbols) EC:DMC or (empty symbols) $\mathrm{EC}_{0.45}: \mathrm{PC}_{0.45}: \mathrm{DMC}_{0.10}$. The dilute solution of $\mathrm{KCl}$ in water is represented by a unitary line. The temperature range was set to $+10{ }^{\circ} \mathrm{C}$ to $+60{ }^{\circ} \mathrm{C}$.

\section{Conclusions}

In conclusion, NaTFSI and $\mathrm{NaPF}_{6}$ in EC:DMC and $\mathrm{EC}_{0.45}: \mathrm{PC}_{0.45}$ : $\mathrm{DMC}_{0.10}$ exhibit similarities to conventional LIB electrolytes both in terms of physico-chemical and molecular properties. In more detail, the EC:DMC based electrolytes display acceptable thermal stability windows of $-30{ }^{\circ} \mathrm{C}$ to $+40{ }^{\circ} \mathrm{C}$, while the ionic conductivities can be as high as $10 \mathrm{mS} \mathrm{cm}^{-1}$ at room temperature for $1 \mathrm{M}$ electrolytes and a fortiori viscosities low. The exchange of DMC for PC greatly inhibits the crystallization processes at the cost of a lower conductivity $\left(6 \mathrm{mS} \mathrm{cm}^{-1}\right.$ at room temperature for $1 \mathrm{M}$ electrolytes) and higher viscosities. From a molecular viewpoint, every studied electrolyte presents a high level of ion dissociation, even if the $\mathrm{NaPF}_{6}$-based electrolytes remain more dissociated regardless of the solvents used. The combination of DFT calculations and Raman spectroscopy 
reveals the importance of several conformers of DMC in the $\mathrm{Na}^{+}$ first solvation shells. While both EC and DMC are found in the solvation shells, there is a faster depletion of EC in the shells with increasing salt concentration why a higher proportion of free EC is found. Furthermore, the use of the fractional Walden rule indicates that $1 \mathrm{M} \mathrm{NaPF}_{6}$ in EC:DMC is more dissociated than $1 \mathrm{M}$ NaTFSI in EC:DMC and furthermore that the addition of PC improves the dissociation. Overall, these data for a wide range of salt concentrations in the most common electrolyte solvents should pave the way for further electrochemical studies, not the least owing to the results on "ultralow" concentrated SIB electrolytes. ${ }^{86}$

\section{Conflicts of interest}

There are no conflicts to declare.

\section{Acknowledgements}

We acknowledge funding received from the European Union's Horizon 2020 research and innovation programme under grant agreement no. 646433 (NAIADES), the ALISTORE-ERI members for many fruitful discussions, and also the funding received from the Swedish Research Council the Swedish Energy Agency (\#37671-1), the Swedish Research Council for Environment, Agricultural Sciences and Spatial Planning, the Severo Ochoa Programme for Centres of Excellence in R\&D (SEV-2015-0496). DM especially acknowledges the European Union for a H2020 MSCA-IF grant no. 74343. PJ is grateful for the continuous financial support from several of Chalmers Areas of Advance: Materials Science, Energy, and Transport. We also acknowledge the computational resources provided by the Swedish National Infrastructure for Computing (SNIC) at Chalmers Centre for Computational Science and Engineering (C3SE).

\section{Notes and references}

1 B. Scrosati and J. Garche, J. Power Sources, 2010, 195, 2419-2430.

2 J. B. Goodenough and Y. Kim, Chem. Mater., 2010, 22, 587-603.

3 B. Dunn, H. Kamath and J. M. Tarascon, Science, 2011, 334, 928-935.

4 V. Etacheri, R. Marom, R. Elazari, G. Salitra and D. Aurbach, Energy Environ. Sci., 2011, 4, 3243-3262.

5 https:/www.nobelprize.org/prizes/chemistry/2019/sum mary/, verified 2020.

6 D. Larcher and J. M. Tarascon, Nat. Chem., 2015, 7, 19-29.

7 http://www.tiamat-energy.com/, verified 18-08-2020.

8 https:/www.altris.se/, verified 18-08-2020.

9 https://www.faradion.co.uk/, verified 18-08-2020.

10 G. Yan, S. Mariyappan, G. Rousse, Q. Jacquet, M. Deschamps, R. David, B. Mirvaux, J. W. Freeland and J.-M. Tarascon, Nat. Commun., 2019, 10, 585.
11 K. Kubota and S. Komaba, J. Electrochem. Soc., 2015, 162, A2538-A2550.

12 L. Li, Y. Zheng, S. Zhang, J. Yang, Z. Shao and Z. Guo, Energy Environ. Sci., 2018, 11, 2310-2340.

13 H. Kim, H. Kim, Z. Ding, M. H. Lee, K. Lim, G. Yoon and K. Kang, Adv. Energy Mater., 2016, 6, 1600943.

14 E. Irisarri, A. Ponrouch and M. R. Palacin, J. Electrochem. Soc., 2015, 162, A2476-A2482.

15 J.-Y. Hwang, S.-T. Myung and Y.-K. Sun, Chem. Soc. Rev., 2017, 46, 3529-3614.

16 D. Monti, A. Ponrouch, M. R. Palacin and P. Johansson, J. Power Sources, 2016, 324, 712-721.

17 A. Ponrouch, D. Monti, A. Boschin, B. Steen, P. Johansson and M. R. Palacin, J. Mater. Chem. A, 2015, 3, 22-42.

18 G. G. Eshetu, G. A. Elia, M. Armand, M. Forsyth, S. Komaba, T. Rojo and S. Passerini, Adv. Energy Mater., 2020, 2000093.

19 M. Á. Muñoz-Márquez, D. Saurel, J. L. Gómez-Cámer, M. CasasCabanas, E. Castillo-Martínez and T. Rojo, Adv. Energy Mater., 2017, 7, 1700463.

20 A. Ponrouch, E. Marchante, M. Courty, J. M. Tarascon and M. R. Palacin, Energy Environ. Sci., 2012, 5, 8572-8583.

21 A. Ponrouch, R. Dedryvere, D. Monti, A. E. Demet, J. M. A. Mba, L. Croguennec, C. Masquelier, P. Johansson and M. R. Palacin, Energy Environ. Sci., 2013, 6, 2361-2369.

22 K. Xu, Chem. Rev., 2014, 114, 11503-11618.

23 R. Mogensen, D. Brandell and R. Younesi, ACS Energy Lett., 2016, 1, 1173-1178.

24 J. Fondard, E. Irisarri, C. Courrèges, M. R. Palacin, A. Ponrouch and R. Dedryvère, J. Electrochem. Soc., 2020, 167, 070526.

25 D. I. Iermakova, R. Dugas, M. R. Palacín and A. Ponrouch, J. Electrochem. Soc., 2015, 162, A7060-A7066.

26 P. K. Nayak, L. Yang, W. Brehm and P. Adelhelm, Angew. Chem., Int. Ed., 2018, 57, 102-120.

27 A. Bhide, J. Hofmann, A. Katharina Durr, J. Janek and P. Adelhelm, Phys. Chem. Chem. Phys., 2014, 16, 1987-1998.

28 P. Walden, Z. Phys. Chem., 1906, 55, 207-249.

29 D. R. MacFarlane, M. Forsyth, E. I. Izgorodina, A. P. Abbott, G. Annat and K. Fraser, Phys. Chem. Chem. Phys., 2009, 11, 4962-4967.

30 C. Schreiner, S. Zugmann, R. Hartl and H. J. Gores, J. Chem. Eng. Data, 2010, 55, 1784-1788.

31 W. Xu and C. A. Angell, Science, 2003, 302, 422-425.

32 C. L. Berhaut, D. Lemordant, P. Porion, L. Timperman, G. Schmidt and M. Anouti, $R S C$ Adv., 2019, 9, 4599-4608.

33 D. M. Seo, S. Reininger, M. Kutcher, K. Redmond, W. B. Euler and B. L. Lucht, J. Phys. Chem. C, 2015, 119, 14038-14046.

34 K. Matsubara, R. Kaneuchi and N. Maekita, J. Chem. Soc., Faraday Trans., 1998, 94, 3601-3605.

35 L. Yang, A. Xiao and B. L. Lucht, J. Mol. Liq., 2010, 154, 131-133.

36 O. Borodin, S.-D. Han, J. Daubert, D. Seo, S.-H. Yun and W. A. Henderson, J. Electrochem. Soc., 2015, 162, A501-A510.

37 A. V. Cresce, S. M. Russell, O. Borodin, J. A. Allen, M. A. Schroeder, M. Dai, J. Peng, M. P. Gobet, S. G. Greenbaum, 
R. E. Rogers and K. Xu, Phys. Chem. Chem. Phys., 2017, 19, 574-586.

38 E. Flores, G. Åvall, S. Jeschke and P. Johansson, Electrochim. Acta, 2017, 233, 134-141.

39 M. J. Frisch, G. W. Trucks, H. B. Schlegel, G. E. Scuseria, M. A. Robb, J. R. Cheeseman, G. Scalmani, V. Barone, B. Mennucci, G. A. Petersson, H. Nakatsuji, M. Caricato, X. Li, H. P. Hratchian, A. F. Izmaylov, J. Bloino, G. Zheng, J. L. Sonnenberg, M. Hada, M. Ehara, K. Toyota, R. Fukuda, J. Hasegawa, M. Ishida, T. Nakajima, Y. Honda, O. Kitao, H. Nakai, T. Vreven, J. J. A. Montgomery, J. E. Peralta, F. Ogliaro, M. Bearpark, J. J. Heyd, E. Brothers, K. N. Kudin, V. N. Staroverov, R. Kobayashi, J. Normand, K. Raghavachari, A. Rendell, J. C. Burant, S. S. Iyengar, J. Tomasi, M. Cossi, N. Rega, J. M. Millam, M. Klene, J. E. Knox, J. B. Cross, V. Bakken, C. Adamo, J. Jaramillo, R. Gomperts, R. E. Stratmann, O. Yazyev, A. J. Austin, R. Cammi, C. Pomelli, J. W. Ochterski, R. L. Martin, K. Morokuma, V. G. Zakrzewski, G. A. Voth, P. Salvador, J. J. Dannenberg, S. Dapprich, A. D. Daniels, Ö. Farkas, J. B. Foresman, J. V. Ortiz, J. Cioslowski and D. J. Fox, Gaussian 09, Gaussian, Inc., Wallingford CT, 2009.

40 X. Bogle, R. Vazquez, S. Greenbaum, A. V. W. Cresce and K. Xu, J. Phys. Chem. Lett., 2013, 4, 1664-1668.

41 A. S. Thomas and A. H. Elcock, J. Am. Chem. Soc., 2006, 128, 7796-7806.

42 P. E. Stallworth, J. J. Fontanella, M. C. Wintersgill, C. D. Scheidler, J. J. Immel, S. G. Greenbaum and A. S. Gozdz, J. Power Sources, 1999, 81, 739-747.

43 P. E. Stallworth, J. J. Fontanella, M. C. Wintersgill, C. D. Scheidler, J. J. Immel, S. G. Greenbaum and A. S. Gozdz, J. Power Sources, 1999, 81-82, 739-747.

44 Y. Zhang, P. Batys, J. T. O'Neal, F. Li, M. Sammalkorpi and J. L. Lutkenhaus, ACS Cent. Sci., 2018, 4, 638-644.

45 J. A. Jaber and J. B. Schlenoff, Macromolecules, 2005, 38, 1300-1306.

46 B. Wunderlich, J. Chem. Phys., 1958, 29, 1395-1404.

47 D. Monti, E. Jonsson, M. R. Palacin and P. Johansson, J. Power Sources, 2014, 245, 630-636.

48 F. Leng, C. M. Tan and M. Pecht, Sci. Rep., 2015, 5, 12967.

49 N. Yang, X. Zhang, B. Shang and G. Li, J. Power Sources, 2016, 306, 733-741.

50 H. Vogel, Phys. Z., 1921, 22, 645-646.

51 G. Tammann and W. Hesse, Z. Anorg. Allg. Chem., 1926, 156, 245-257.

52 G. S. Fulcher, J. Am. Ceram. Soc., 1925, 8, 789-794.

53 M. Dahbi, F. Ghamouss, F. Tran-Van, D. Lemordant and M. Anouti, J. Power Sources, 2011, 196, 9743-9750.

54 Y. Sasaki, M. Takehara, S. Watanabe, N. Nanbu and M. Ue, J. Fluorine Chem., 2004, 125, 1205-1209.

55 S. I. Lee, U. H. Jung, Y. S. Kim, M. H. Kim, D. J. Ahn and H. S. Chun, Korean J. Chem. Eng., 2002, 19, 638-644.

56 Y. R. Dougassa, J. Jacquemin, L. El Ouatani, C. Tessier and M. Anouti, J. Phys. Chem. B, 2014, 118, 3973-3980.

57 K. Hayashi, Y. Nemoto, S. Tobishima and J. Yamaki, Electrochim. Acta, 1999, 44, 2337-2344.
58 C. W. Walker, J. D. Cox and M. Salomon, J. Electrochem. Soc., 1996, 143, L80-L82.

59 A. Bankura, V. Carnevale and M. L. Klein, J. Chem. Phys., 2013, 138, 014501.

60 Y. Zeng, J. Hu, Y. Yuan, X. Zhang and S. Ju, Chem. Phys. Lett., 2012, 538, 60-66.

61 J.-M. Thiebaut, J.-L. Rivail and J.-L. Greffe, J. Chem. Soc., Faraday Trans. 2, 1976, 72, 2024-2034.

62 J. E. Katon and M. D. Cohen, Can. J. Chem., 1974, 52, 1994-1996.

63 J. E. Katon and M. D. Cohen, Can. J. Chem., 1975, 53, 1378-1386.

64 T. A. Pham, K. E. Kweon, A. Samanta, V. Lordi and J. E. Pask, J. Phys. Chem. C, 2017, 121, 21913-21920.

65 D. Spångberg and K. Hermansson, Chem. Phys., 2004, 300, 165-176.

66 P. Johansson, M. Edvardsson, J. Adebahr and P. Jacobsson, J. Phys. Chem. B, 2003, 107, 12622-12627.

67 B. Fortunato, P. Mirone and G. Fini, Spectrochim. Acta, Part A, 1971, 27, 1917-1927.

68 B. Klassen, R. Aroca, M. Nazri and G. A. Nazri, J. Phys. Chem. $B, 1998,102,4795-4801$.

69 S. A. Hyodo and K. Okabayashi, Electrochim. Acta, 1989, 34, 1557-1561.

70 L. Aguilera, J. Scheers and A. Matic, Phys. Chem. Chem. Phys., 2016, 18, 25458-25464.

71 M. Morita, Y. Asai, N. Yoshimoto and M. Ishikawa, J. Chem. Soc., Faraday Trans., 1998, 94, 3451-3456.

72 J. C. Lassegues, J. Grondin and D. Talaga, Phys. Chem. Chem. Phys., 2006, 8, 5629-5632.

73 D. Brouillette, D. E. Irish, N. J. Taylor, G. Perron, M. Odziemkowski and J. E. Desnoyers, Phys. Chem. Chem. Phys., 2002, 4, 6063-6071.

74 A. Bakker, S. Gejji, J. Lindgren, K. Hermansson and M. M. Probst, Polymer, 1995, 36, 4371-4378.

75 M. Herstedt, M. Smirnov, P. Johansson, M. Chami, J. Grondin, L. Servant and J. C. Lassegues, J. Raman Spectrosc., 2005, 36, $762-770$.

76 X. Xuan, J. Wang and H. Wang, Electrochim. Acta, 2005, 50, 4196-4201.

77 R. Aroca, M. Nazri, G. A. Nazri, A. J. Camargo and M. Trsic, J. Solution Chem., 2000, 29, 1047-1060.

78 M. Nie, D. P. Abraham, D. M. Seo, Y. Chen, A. Bose and B. L. Lucht, J. Phys. Chem. C, 2013, 117, 25381-25389.

79 M. Morita, Y. Asai, N. Yoshimoto and M. Ishikawa, J. Chem. Soc., Faraday Trans., 1998, 94, 3451-3456.

80 J. Arai, K. Nishimura, Y. Muranaka and Y. Ito, J. Power Sources, 1997, 68, 304-306.

81 Y. Marcus and G. Hefter, Chem. Rev., 2006, 106, 4585-4621. 82 I. Geoffroy, P. Willmann, K. Mesfar, B. Carre and D. Lemordant, Electrochim. Acta, 2000, 45, 2019-2027.

83 A. Webber, J. Electrochem. Soc., 1991, 138, 2586-2590.

84 E. W. Greene and J. W. Williams, Phys. Rev., 1932, 42, 119-140.

85 G. P. Srivastava and Y. P. Varshni, Physica, 1956, 22, 584-586.

86 Y. Li, Y. Yang, Y. Lu, Q. Zhou, X. Qi, Q. Meng, X. Rong, L. Chen and Y.-S. Hu, ACS Energy Lett., 2020, 5, 1156-1158. 